\title{
1 Interdisciplinary Urban Complexity Research and Texts as Qualitative Models
}

This chapter attempts to sketch a literary and cultural studies approach to the modelling of urban complexity: After briefly commenting on what I perceive as a neglect of cultural phenomena in much urban modelling, I will discuss key characteristics of urban complexity from a literary and cultural studies perspective and will relate these to technical or mathematical notions of complexity. My third section engages with the need for reduction and compression in modelling and with the resulting limitations of urban models before discussing the fundamentally different status of the model in urban complexity studies on the one hand and in literary and cultural studies on the other hand. The chapter thus sets out to show how literary and cultural studies engage with urban complexity and what such an engagement can contribute to truly interdisciplinary work on urban complexity and urban systems. I will argue that literary texts specifically can bring back into the discussion those features of urban complexity that resist quantitative modelling but that are nonetheless crucial to a differentiated understanding of the functioning of urban systems.

\section{The Neglect of 'Culture' in Urban Complexity Research}

In his masterful study Die komplexe Stadt: Orientierungen im urbanen Labyrinth (2009), one of the most ambitious attempts to provide urban studies with an integrating research agenda, Frank Eckardt goes so far as to propose complexity as the key characteristic of the city and calls for a transdisciplinary research programme organised around the integrating paradigm of 'complexity'. However, Eckardt then largely pursues a sociological programme.

'Complexity' is indeed central to much work in urban modelling (cf. for instance Albeverio et al.; Batty 2013; Portugali 2011; Walloth/Gurr/Schmidt; for a brief and accessible account, cf. Gurr/Walloth). Inter- and transdisciplinary methodological discussions of urban modelling might highlight questions such as the following:

- How is 'urban complexity' understood, defined and 'modelled' in various disciplines and what is the relation to urban reality these models claim? 
- Which subsystems or combinations of subsystems are being modelled by researchers of various disciplines - e.g. is the city considered as a social, ecological, economic, technical or cultural system?

- What are the - normative and/or descriptive - aims and interests pursued with different types of models? Are they designed fundamentally to understand interdependencies within or explain the functioning of urban systems - or do they seek to aid decision-making in concrete situations?

- How can central non-quantifiable phenomena that are especially relevant to a 'humanities' understanding of urban complexity be integrated into the dominant types of models? To what extent can they complement mathematical models?

- Which issues and strategies in dealing with urban complexity are already cross-disciplinary? What are the interfaces between disciplines and what bridges can be built here?

- Which of the issues and strategies specific to the individual disciplines dealing with urban complexity can be regarded as complementary? What are the implications of the specific sign systems in which these models are mediated? Are there parallels or analogies between quantitative and narrative models?

- According to which criteria do we make decisions concerning parameters to be included or excluded? To what extent are selection criteria for inclusion and exclusion complementary in different disciplines?

- How can the insights from various types of models be integrated?

It seems that, despite much talk of multi-, inter- or transdisciplinary research in (urban) complexity, the perspective of culture is curiously absent in discussions of urban modelling. ${ }^{1}$ More specifically, while the consideration of actors and groups of actors and their behaviour as an important dimension of 'culture' as studied by the social sciences is clearly central to modelling endeavours, patterns of symbolic representation and patterns of perception and interpretation as less tangible elements of the city largely resist quantitative modelling and are a conspicuous absence in models of urban complexity. A few prominent examples may suffice here: The "Preface" to one of the most ambitious collections on the topic, Albeverio et al.'s The Dynamics of Complex Urban Systems (2008), in its plea for a "fruitful collaboration between natural science" and "regional science" mentions "physics, mathematics, computer science, biology ..." (omission original) on the side of "natural science" and "architecture, geography, city plannings [sic], economics, sociology ..." (omission original) on the side of "regional science" ( $\mathrm{v}$ ) - and the volume, comprehensive as it is, does not contain anything even remotely from the field of cultural studies. Even in the exhaustive and masterful 2009 Encyclopedia of Complexity and Systems Science, Michael Batty's state-of-the-art contribution on "Cities as Complex Systems: Scaling, Interaction, Networks, Dynamics and Urban Morphologies" (1041-1071) does not even mention 'culture', nor do concepts like 'individuality' play any role. Similarly, "Springer Complexity”, according to the description for what is arguably the leading and most prominent book 
series in the field, is said to "cut across all traditional disciplines of the natural and life sciences, engineering, economics, medicine, neuroscience, social and computer science" (Portugali et al. front matter). Moreover, the outline for Springer's "Understanding Complex Systems" (UCS) series states the aim of the programme as follows: "UCS is explicitly transdisciplinary", its first "main goal" being "to elaborate the concepts, methods and tools of complex systems at all levels of description and in all scientific fields, especially newly emerging areas within the life, social, behavioural, economic, neuro- and cognitive sciences (and derivatives thereof)" (Portugali 2011, front matter). The mental, non-institutional dimension of culture in the form of symbolically mediated patterns of perception and interpretation of human environments, it seems, hardly features in discussions of urban complexity.

\section{Characteristics of (Urban) Complexity: Urban Systems Research and the Perspective of Literary and Cultural Studies}

Many of the characteristics of urban complexity frequently discussed in research on complex urban systems ${ }^{2}$ are those that are also of interest to literary and cultural studies. Portugali (2006) conveniently defines the complexity of the city thus: "a very large number of interacting parts, linked by a complex network of feedback and feedforward loops, within a system that is open to and, thus part of, its environment" (657; cf. also Portugali 2011, 232). Further characteristics of complexity frequently discussed include selforganisation, emergence, non-linearity, phase transitions, density, mobility (as one cause of change over time and as the occasion for increased interaction and mixing), ethnic and cultural multiplicity, heterogeneity and hybridity, violence, conflicts over the use of space, intersections of technology and virtual spaces with physical spaces, overlapping and intersecting spatial scales from the local to the global - and their interdependencies, as well as complex interferences, interdependencies or intersections in the interaction between multiple players, intentions or force fields. Together, these make urban systems prime examples of translocal networks of complex relationships, connections and interdependencies subject to rapid change over time. Moreover, as already indicated in Portugali's working definition, the city is of course an open or dissipative rather than a closed system (in the technical sense): It exchanges goods, energy, information, people, money, etc. with its environment. All these characteristics, it seems, are more or less part and parcel also of urban simulation models in the more technically oriented disciplines concerned with urban modelling from a complex systems perspective.

However, the 'softer', less easily quantified and modelled characteristics of urban complexity are no less central to the 'urban experience'. In this vein, in addition to the 'usual suspects' such as "hierarchy and emergence, non-linearity, asymmetry, number of relationships, number of parts", Mainzer (374) also lists the following features: "values and beliefs, people, interests, notions and perceptions" (they appear in a visualisation, hence in no particular order - the order is mine). Additionally, while the notion of a system's 'history' - in the 
sense that previous developments have an impact on the present and future course of the system - is central to urban modelling (if only in the sense that past developments can be extrapolated for predictive purposes), one specific aspect of a city's history is of particular importance to an understanding of urban systems from the perspective of literary and cultural studies: This is the notion of the city as a palimpsest, a form of layered spatialised memory (this is discussed in detail in Chapters 3 and 4). ${ }^{3}$ Individual and collective memory and the way it is physically manifested in and evoked by the built environment is a prime concern in many literary texts (for a detailed discussion of a specific key text, cf. Chapter 3).

Arguably the central challenge to literary 'modelling', however, lies in the multiplicity of sense impressions and the resulting sensual overload and semiotic 'overkill' as a result of a multiplicity of sign systems and ceaseless semiosis. In this vein, Georg Simmel in his influential 1903 essay "The Metropolis and Mental Life", one of the crucial texts in the early phase of urban studies, defines "the psychological conditions which the metropolis creates" as marked by the "intensification of nervous stimulation which results from the swift and uninterrupted change of outer and inner stimuli [...] the rapid crowding of changing images, the sharp discontinuity in the grasp of a single glance, and the unexpectedness of onrushing impressions" (13; italics original).

In his 2011 study Complexity, Cognition and the City, in a remarkably similar way, Portugali speaks of

the really complex situation that concerns individuals under a bombardment of information, that is, under a multiplicity of messages from a multiplicity of sources and of all kinds. This is typical of the dynamics of cities: every agent operating in the city is continually subject to a multiplicity of messages in the form of views, noises, smells etc. In order to behave and survive, the agent $[. .$.$] must make sense of all those signals and messages.$

(232f.)

As I will argue in Chapter 2, it is precisely the representation of simultaneity that poses the greatest challenge in the narrative representation of urban complexity.

\section{Urban Complexity in Technical and Literary Models: Information, Compression, the Limits of Modelling - and the Status of the Model}

In two chapters jointly authored with Herman Haken that largely go back to an earlier joint essay (Haken/Portugali), Portugali (2011) elaborates on the amount of information contained in the physical structure of the city. ${ }^{4}$ In the subchapter tellingly entitled "How Many Bits to the Face of the City" (179186), the authors argue: "From the point of view of information theory, the face of the city is a message. As a message it conveys and transmits different quantities of Shannonian information" (Portugali 2011, 201). Conceived in 
terms of informational complexity, it is obvious that the city contains a virtually endless amount of information - even if we just take its physical shape and ignore, for the moment, the interaction of millions of humans each with their own thoughts, hopes, anxieties, etc.

As far as the 'measurement' of complexity from a literary and cultural studies perspective is concerned, it is evident that most mathematical or technical measures are hardly helpful: Neither algorithmic or Kolmogorov complexity (a measurement of the length of the minimal programme that reproduces a given sequence; for a discussion, cf. Li/Vitányi), nor Bennett's notion of logical depth (essentially a measure of the time required for a given bit string to be computed and reproduced), nor effective complexity in the sense of Gell-Mann (for a discussion, cf. for instance Gell-Mann 1995a and 1995b), nor the measure of informational entropy, nor the question of calculability as in P- or NP-problems, nor dynamic complexity are really helpful here. It seems that, when descriptions of urban systems and the specific forms of complexity they exhibit are concerned, it does not really matter whether we are looking at Kolmogorov complexity, effective complexity or logical depth the multiple interdependencies, overlapping scales, forms of self-organisation, etc., yield an astonishing degree of complexity by any definition. However, this complexity is not beyond comprehension or calculability: "The significant achievement of complexity theories is to show that even [under such complex conditions] a scientific approach is possible" (Portugali 2011, 232). The solution, Portugali argues, lies in what he refers to as "information compression" (2011, 231-233).

Compression and strategic 'reduction' of complexity are of course part and parcel of any modelling process, as Stachowiak's notion of "reduction" ["Verkürzung"] as central to any model already makes clear (132). The crucial task, of course, is to decide what can safely be left out or abstracted so as not to distort the overall picture. This will naturally depend on what the model is supposed to achieve - whether, for instance, to help understand all interdependencies within a system or whether to capture only those features of a system perceived as relevant to a specific investment decision. In both cases, the heuristic nature of the model is not to be ignored. In this context, Cohen and Stewart aptly remark:

Mathematical descriptions of nature are not fundamental truths about the world, but models. There are good models and bad models and indifferent models, and what models you use depends on the purposes for which you use it and the range of phenomena which you want to understand [...] Reductionist rhetoric [...] claims a degree of correspondence between deep underlying rules and reality that is never justified by any actual calculation or experiment.

Lefebvre similarly comments on the need for reduction in dealing with 'complexity' but also on the inherent dangers: 
Reduction is a scientific procedure designed to deal with complexity and chaos of brute observations. This kind of simplification is necessary at first, but it must be quickly followed by the gradual restoration of what has thus been temporarily set aside for the sake of analysis. Otherwise a methodological necessity may become a servitude, and the legitimate operation of reduction may be transformed into the abuse of reductionism.

(105f.; italics original)

In a related vein, David Byrne in an excellent overview on Complexity Theory and the Social Sciences aptly remarks that complexity science is "clearly quantitative" (54) in its aims and methods, and appropriately points out three more fundamental caveats and limits to quantitative analysis and modelling:

1. the limits to formalisation of any mathematical system established by Gödel;

2. the limits to capacity of measurement central to deterministic chaos; and

3. the working limits for expression of mathematical formalism derived from the non-linearity of the real systems with which chaos/complexity is concerned

(for an excellent discussion of these caveats, cf. 54-71)

More specifically and with a view to practical limitations in the modelling of urban systems, Portugali (2012a) in an enlightening state-of-the-art article on "Complexity Theories of Cities: Achievements, Criticism and Potentials", comments on a key problem in many contemporary applications of complexity theory in urban modelling:

There is nothing wrong $[\ldots]$ in sophisticated simulation models crunching huge quantities of data by means of fast computers. What's wrong is [...] that simulation models originally designed as media by which to study phenomena of complexity and self-organization become the message itself.

As a result, "practitioners of urban simulation models tend to overlook the non-quantifiable urban phenomena" (52)..$^{5}$

In his "Introduction" to the same volume, Portugali $(2012 \mathrm{~b}, 4)$ attempts to account for this loss by commenting on the research motivation of scholars in CTC (complexity theories of cities): "Some are physicists for whom cities is [sic] just another source for quantitative data with which to test their models, while others are urbanists who see CTC as the new and more sophisticated generation of the 'old' quantitative approach to cities. By so doing they overlook the qualitative message of CTC" (4). ${ }^{6}$ He then incisively asks: "But what about the uniqueness of cities - of the properties that differentiate them from material and organic entities, how do these [relate] to their complexity and dynamics?" (4). Thus, what is missing, according to Portugali, is only the 
analysis of what distinguishes cities generally from other complex systems; he does not appear to be interested in the arguably more important question what makes an individual city unique - as in studies on the "intrinsic logic ['Eigenlogik'] of cities" (cf. Berking/Löw) - let alone in the uniqueness of individuals and their response to the city.

What is the consequence of this type of reduction? While Rolf Lindner (92) has argued that " $[t]$ he city of sociologists $[. .$.$] is frequently a non-sensual place,$ a city one does not hear, smell, taste, more precisely, a Non-Place", 7 I would argue that this is even more true of the city of quantitative modellers and complexity theorists.

Purely quantitative approaches are similarly problematic when it comes to defining the elusive notion of 'urbanity' or when it comes to defining the 'metropolis': 'Metropolis' and, to a lesser extent, 'city', it seems, are not merely descriptive terms, but more or less strongly imply normative elements, even a utopian promise - and this, I would argue, is largely a cultural promise that is difficult to categorise. However, the concept of the metropolis of course is not only normative. It does make sense to classify cities according to various criteria, and many historical as well as recent attempts to define the metropolitan character of cities are very enlightening. ${ }^{8}$ Thus, the concept of 'metropolis' just like 'urbanity' - curiously oscillates between descriptively designating a quantifiable status of centrality as a financial centre, a traffic node, a centre of research and education or of the media industry on the one hand, and a normative requirement of a far less tangible 'je ne sais quoi', a metropolitan 'feel' of cultural promise (for a more detailed discussion, cf. Gurr 2010, 2015): Frankfurt/Main may be a financial metropolis, because, second to London, it is the seat of the most important European stock exchange and of several important banks, but is it a cultural metropolis? Berlin, although certainly not a financial centre, is a metropolis, because it is a capital with over three million residents, but it also appears to have the intangible cultural 'flair' a metropolis in the wider sense also seems to need. Even in scholarly discourse, the descriptive and the normative components of the concept of 'metropolis' are not always neatly distinguished. Despite their undisputed achievements in dealing with a range of aspects of urban complexity - demographic developments, material and energy flows, mobility planning and innumerable others - it is here, in understanding the qualitative phenomena such as urbanity, individuality, place-specificity, individual patterns of interpretation and sense-making that quantitative models show their limitations.

This, I argue, is where literary and cultural studies come in: For although it is, of course, possible to include certain 'subjective' features into a model (for instance by including group-specific cultural preferences, as is common in agent-based modelling and other types of urban simulation models), what is individual, unique, historically and personally specific and not reducible to an underlying pattern, is what disappears in abstracting from the individual and in the aggregation of preferences, needs, desires, hopes, fears into an equation. It is precisely this individuality and specificity both of different urban environments in their "intrinsic logic" (sensu Berking/Löw) and of human behaviour, of perceptions and patterns of sense-making that literary texts model in 
uniquely differentiated ways. It is in literary texts that the "non-sensual" city of sociologists (sensu Lindner) and quantitative modellers becomes perceptibly individualised. ${ }^{9}$

From the perspective of literary and cultural studies, the question is how the complexity of the urban text is 'modelled' in literature (and other media, though I do not discuss them here). Despite the universally diagnosed importance of complexity as a key characteristic of the urban and despite the widely perceived affinity between the city and the novel (and film) - and a look at innumerable 'urban' poems and narrative fictions confirms that the issue is indeed central to 'urban literature' - the specific issue of how literary texts represent urban complexity has received very limited explicit scholarly attention. In most of the innumerable studies on urban imaginaries in literature and film, though occasionally implied, complexity - let alone simultaneity - almost universally does not feature as a theme in itself. ${ }^{10}$

A further key issue that needs to be addressed in comparative discussions of 'urban modelling' in technical complexity research and in literary studies is the fundamentally different status of the 'model' in both fields: While in technical urban complexity research, the model is the result of scientific endeavour, in literary and cultural studies, the literary text functions as the 'model' and is thus the object of study rather than the result of the scholar's own work. Thus, Mahr's rather casually enumerative formulation of the two alternative ways in which models come into being - "no object is a model per se. Models are built or chosen" (331; italics original) - here constitutes a fundamental distinction between different research cultures and their dominant forms of engaging with models.

\section{Bridging the Gap: Parallels between Quantitative and Textual Models}

Despite the fundamentally different status of the 'model' in urban complexity modelling on the one hand and in literary and cultural studies on the other hand, there are a number of important parallels and points of intersection between the two types of 'model' and in the understanding of complexity: What most technical notions of complexity share is that they measure the complexity of a system in terms of the length or the complexity of the description or representation of that system. A number of complexity theorists have even argued that "complexity is not primarily a characteristic of the object that is being described, but of the description" (Richter/Rost 112; my translation). ${ }^{11}$ This notion might lend itself as a bridge between technical or mathematical and cultural conceptualisations of complexity. Ultimately, what is relevant to literary studies, one might argue, is not so much the complexity of the city itself, but the representation of this complexity, i.e. its description in the 'model' of the literary text. Literary studies are thus concerned with the challenge of 'modelling' it, or, in the terminology of literary studies, of 'representing' it. Thus, where technical and mathematical complexity research is concerned with the mathematical description of complexity, literary and cultural studies of urban complexity are concerned with the challenges of verbal representation. 
Gell-Mann's notion of "effective complexity” provides a further important connection between a technical and a literary understanding of complexity:

A measure that corresponds much better to what is usually meant by complexity in ordinary conversation, as well as in scientific discourse, refers not to the length of the most concise description of an entity (which is roughly what AIC [algorithmic information content] is), but to the length of a concise description of a set of the entity's regularities. Thus something almost entirely random, with practically no regularities, would have effective complexity near zero. So would something completely regular, such as a bit string consisting entirely of zeroes. Effective complexity can be high only in a region intermediate between total order and complete disorder.

This seems precisely to be the case with cities: In the sense of "effective complexity", they are systems in which there are multiple regularities as well as contingencies, and hence systems in which "a concise description of a set of the entity's regularities" would be extremely long. Thus characterised by an intricate combination of both order and disorder, cities have long been understood as systems of extremely high "effective complexity" (take Jane Jacobs's classic formulation that cities are "problems in organized complexity", 449). Somewhat speculatively, we might argue that literary texts as models of reality are per se combinations of order and disorder: In frequently highly structured and ordered ways, they represent complexity and multiplicity, even disorder, and overlay disorder with order - established plot structures, schemata or typological patterns of interpretation (cf. Koschorke 29ff.) - and thus structurally replicate key patterns of urban complexity (for a detailed discussion of texts as structural and functional urban models, cf. Chapter 3; for the structural analogies between city and text, cf. also Sharpe/Wallock).

Moreover, if we regard 'scenario building' and the testing of alternative parameter settings in their impact on a given system as a crucial function of urban systems modelling - a notion I discuss in some detail in Chapter 6 then a further parallel emerges: One of the central functions of literature, according to one understanding, is that it serves as a form of symbolic action, as a social experiment free from the constraints of everyday life - literature as 'de-pragmatised behaviour in rehearsal' ['entpragmatisiertes Probehandeln'] ${ }^{12}$ which makes it possible symbolically to try out in fiction different scenarios or potential solutions for key societal issues. Here, too, given the descriptive, representational as well as the - at least implicitly - prescriptive, speculative, exploratory function of texts, this conceptualisation - developed in the wake of Mahr's understanding of the model - of texts as both descriptive "models of" and prescriptive "models for" urban structures, developments and functions, seems highly appropriate.

The different procedures used in different fields and disciplines to represent, reduce (or: constitute in the first place) and seek to 'manage' complexity do 
justice to different facets of urban complexity in varying degrees: Mobility systems or energy flows lend themselves to being modelled in the sense of complex systems research far more than do processes of sense-making or conflicting patterns in the perception and use of space, which find privileged expression in verbal models of literary texts. Even the selection criteria for facets to be included in (and, conversely, excluded from) the model are virtually diametrically opposed: that which is individual, specific or characteristic in literary texts as opposed to that which can be generalised, aggregated and quantified in quantitative models.

Moreover, the boundaries between numerical, visual and narrative models do not necessarily coincide with disciplinary boundaries, as the example of modelling urban complexity in social cartography shows (for a detailed discussion cf. Gurr/Schneider; for questions of statistics and cartography, cf. Schneider 2006, 2011a, 2011b, 2014; for mapping in literary studies, cf. Mattheis; Moretti; Rossetto): Here, visualisations are regularly preceded by quantitative models, which in turn may be informed by underlying - often unquestioned - narratives. Similar forms of overlay and transfer between quantitative and visual models are to be found in different methods of mathematical optimisation such as graph theory or in the geometrical 'tesselation' of areas as they occur in the optimisation of infrastructures, logistics networks, scheduling problems or evacuation scenarios. What is more, qualitative and quantitative representations of complexity by no means have to correspond: some forms of complexity may be easy to describe qualitatively but may be extremely difficult to quantify (and vice versa).

Nonetheless, a number of strategies in dealing with complexity are rather similar, and there are a large number of overlaps, interactions and transfers between different basic types of models. There are, for instance, a number of remarkable parallels and analogies between algorithmic and aesthetic/literary strategies of representing and reducing complexity (sometimes only reduction may make representation possible in the first place). Thus, a number of literary strategies of reducing complexity - for instance, the metonymic strategy of telling one story and suggesting that innumerable others would also have been worth telling, or the breaking of linearity by means of partition and distribution (for a typology of such strategies, cf. Chapter 2) - are paralleled in mathematics and information technology in the handling of complex calculations and large quantities of data by means of distributed computing, randomisation or decomposition (for an accessible discussion, cf. Schultz). ${ }^{13}$

Despite such parallels, analogies and processes of exchange, the different methods of modelling complexity cannot be seamlessly integrated or converted into one another: My point is not that key qualitative elements of the urban should somehow nonetheless be quantified in order to be integrated into numerical models after all. Such different models might rather complement each other, for instance by mutually setting off shortcomings and by filling in each other's blind spots. This kind of integration of various approaches to modelling, I argue, is crucial to a more refined understanding of complex urban systems. 


\section{Urban Complexity Research}

What, then, can the study of cities and urban complexity learn from literary and cultural studies? It may be the insight that the irreducible element of individual psychological responses to a given urban environment, that is, human desires, hopes and fears, are very often crucial to understanding that environment. What literary and cultural studies as I conceive them can contribute is an understanding of precisely those elements of urban complexity that cannot be measured, modelled, classified or studied in terms of information theory. Literary texts as an alternative form of 'modelling' urban complexity enable different views and may draw attention to blind spots in other models, thus not only functioning as a type of 'sanity check' but as a further, different and complementary type of 'urban model'.

Further inter- and transdisciplinary research across the disciplines should enlarge on the implications of differences and complementarities between different types of models. What seems clear, however, is that insights into the limitations of quantitative models and the complementary achievements of qualitative models productively tie in with recent insights into the limits of planning and plannability, with discussions of planning under and for conditions of uncertainty, or of the role of emergent processes for the practice of planning - what can be planned is very often not what will make a place distinctive (cf. for instance Walloth 2014, 2016). These discussions therefore also tie in with notions of a 'new modesty' in planning. It is precisely the need to integrate these different perspectives to come to a meaningful understanding of the complex dynamic of 'urban systems' that makes this kind of interdisciplinary dialogue so necessary, so challenging and so rewarding.

\section{Notes}

1 The same is true of the roles and functions of urban culture in urban systems. For discussions of the functions of urban culture and the contribution of urban cultural studies to transdisciplinary urban research, cf. for instance Butler/Gurr; Gurr/Butler 2011, 2013.

2 For enlightening explicit or implicit definitions of urban complexity and its defining features, cf. for instance Batty 2009, passim; Eckardt passim; Mainzer 374 et passim; Portugali 2000; Portugali 2006, 652-657 et passim; Portugali 2011, $232 \mathrm{ff.}$ et passim; Portugali 2012b, 4f.

3 For various aspects of the notion of the city as a palimpsest, cf. Assmann; Harvey 66; Hassenpflug 2006, 2011; Huyssen; Martindale; Sharpe/Wallock 9; Suttles. For the palimpsest in literary studies, cf. especially Dillon.

4 Cf. Portugali 2011, ch. 8: "Shannonian Information and the City" (167-187) and ch. 9: "Semantic Information and the City" (187-210); cf. also Haken/Portugali.

5 Similarly, Portugali (2012a, 54) argues that "[q]ualitative urban phenomena do not lend themselves to quantitative-statistical analysis and thus are of little interest to mainstream CTC".

6 Portugali $(2011,227)$ somewhat schematically accounts for this by commenting on the different methodologies of the natural as opposed to the social sciences: "The methodological tools of the 'hard' sciences are reductionism, mathematical formalism, statistical analysis and explanation, while those of the 'soft' humanities and social theory are the exact opposite: anti-reductionism, understanding in place of 
explanation, and hermeneutics in place of analysis." Like Portugali, Mainzer calls for a recognition of the qualitative features of a system and argues that complexity science can function as a connection: "Contrary to any reductionistic kind of naturalism and physicalism we recognize the characteristic intentional features of human societies. Thus the complex system approach may be a method of bridging the gap between the natural sciences and the humanities that was criticized in Snow's famous 'two cultures'” (12). For an enlightening if frequently schematic problematisation of "the two cultures" in the context of complexity theories and cities, cf. Portugali 2011, 9-52; cf. also Stephen Read and several other contributions in Portugali et al.

7 The German original reads: "Die Stadt der Soziologen hingegen ist für gewöhnlich ein unsinnlicher Ort, eine Stadt, die man nicht hört, nicht riecht, nicht schmeckt, genau genommen ein Nicht-Ort" (Lindner 92). Marc Augé's notion of the "nonplace" is not quoted here, but clearly implied, it seems.

8 Cf. especially Danielzyk/Blotevogel, who distinguish between the (1) innovation and competition function, (2) decision and control function, (3) gateway function, and (4) symbolic function. For an early influential study, cf. Hall; for a widely debated recent contribution, cf. Sassen; for a survey, cf. Bronger.

9 Here, the inquiry into the "knowledge of literature" (cf. Hörisch; my italics) or into the strategies of producing knowledge in literature may be especially relevant: What are the specific achievements of literature and of literary texts as a unique form of generating, storing, transmitting and mediating knowledge (cf., for instance, Felski; Fluck; Gurr 2013; Gymnich/Nünning)? It has been argued that literary texts represent knowledge - or create it in the first place - in ways fundamentally different from discursive, expository texts (cf., for instance, Glomb/Horlacher; Hörisch). Specific literary strategies thus become "devices for articulating truth" (Felski 84). This centrally concerns questions of genre and questions of literary modelling generally: In which ways do literary (and maybe especially poetic) texts function differently from discursive texts (for an example, cf. Gurr 2017) or what are the specific cognitive achievements of narrative as opposed to, say, quantitative models of complex matters?

10 Cf. for instance Alter; Balshaw/Kennedy; Barta; Brooker 1996, 2002; Caws; Harding; Keunen/Eeckhout; Lehan; Lenz/Riese; McNamara; Scherpe; Smuda; Teske; Wirth-Nesher; Wolfreys 1998, 2004, 2007. A few observations on urban complexity are to be found, for instance, in Keunen or Brandt.

11 The German original reads: "Komplexität ist nicht in erster Linie eine Eigenschaft des beschriebenen Objekts, sondern der Beschreibung selbst” (Richter/Rost 112).

12 This is the view formulated, among others, by Kenneth Burke, Dieter Wellershoff, Wolfgang Iser or Glomb/Horlacher.

13 I am grateful to Alf Kimms, professor of Logistics and Operations Research at the University of Duisburg-Essen's Mercator School of Management, and an expert on quantitative strategies of optimisation, for helpful discussions on these parallels.

\section{References}

Albeverio, Sergio, Denise Andrey, Paolo Giordano, Alberto Vancheri, eds. The Dynamics of Complex Urban Systems: An Interdisciplinary Approach. Heidelberg: Physica, 2008.

Alter, Robert. Imagined Cities: Urban Experience and the Language of the Novel. New Haven: Yale University Press, 2005. 


\section{Urban Complexity Research}

Assmann, Aleida. "Geschichte findet Stadt." Kommunikation - Gedächtnis - Raum: Kulturwissenschaften nach dem 'Spatial Turn.' Ed. Moritz Csàky, Christoph Leitgeb. Bielefeld: transcript, 2009. 13-27.

Augé, Marc. Non-Places: Introduction to an Anthropology of Supermodernity. London: Verso, 1995.

Balshaw, Maria, Liam Kennedy. "Introduction." Urban Space and Representation. Ed. Balshaw, Kennedy. London: Pluto, 2000. 1-21.

Barta, Peter I. Bely, Joyce, and Döblin: Peripatetics in the City Novel. Gainesville: University Press of Florida, 1997.

Batty, Michael. "Cities as Complex Systems: Scaling, Interaction, Networks, Dynamics and Urban Morphologies." Encyclopedia of Complexity and Systems Science. Ed. Robert A. Meyers. Berlin: Springer, 2009. Vol. 1, 1041-1071.

Batty, Michael. The New Science of Cities. Cambridge, MA: MIT Press, 2013.

Berking, Helmuth, Martina Löw, eds. Die Eigenlogik der Städte: Neue Wege für die Stadtforschung. Frankfurt/Main: Campus, 2008.

Brandt, Stefan L. "The City as Liminal Space: Urban Visuality and Aesthetic Experience in Postmodern U.S. Literature and Cinema." Amerikastudien/American Studies 54.4 (2009): 553-581.

Bronger, Dirk. Metropolen - Megastädte - Global Cities: Die Metropolisierung der Erde. Darmstadt: Wissenschaftliche Buchgesellschaft, 2004.

Brooker, Peter. Modernity and Metropolis: Writing, Film and Urban Formations. Houndmills: Palgrave, 2002.

Brooker, Peter. New York Fictions: Modernity, Postmodernism, the New Modern. London: Longman, 1996.

Burke, Kenneth. The Philosophy of Literary Form: Studies in Symbolic Action. Berkeley: University of California Press, 1974 [reprint; orig. ed.: Baton Rouge: Louisiana State University Press, 1941].

Butler, Martin, Jens Martin Gurr. "Urbane Populärkultur als Bewertungspraxis und -ressource: Zum normativen Potential populärkultureller Inszenierung und diskursiver Aneignung urbaner Räume.” Place-Making in urbanen Diskursen. Ed. Ingo H. Warnke, Beatrix Busse. Berlin, Munich, Boston: de Gruyter, 2014. 369-384.

Byrne, David. Complexity Theory and the Social Sciences: An Introduction. London, New York: Routledge, 1998.

Caws, Mary Ann, ed. City Images: Perspectives from Literature, Philosophy, and Film. New York: Gordon and Breach, 1991.

Cohen, Jack, Ian Stewart. The Collapse of Chaos: Discovering Simplicity in a Complex World. Harmondsworth: Penguin, 1995.

Danielzyk, Rainer, Hans Heinrich Blotevogel. "Leistungen und Funktionen von Metropolregionen." Metropolregionen und Raumentwicklung, Part 3: Metropolregionen. Innovation, Wettbewerb, Handlungsfähigkeit. Ed. Jörg Knieling. Hannover: Verlag der ARL, 2009. 22-29.

Dillon, Sarah. The Palimpsest: Literature, Criticism, Theory. New York: Continuum, 2007.

Eckardt, Frank. Die komplexe Stadt: Orientierungen im urbanen Labyrinth. Wiesbaden: Verlag für Sozialwissenschaften, 2009.

Felski, Rita. Uses of Literature. Oxford: Blackwell, 2008.

Fluck, Winfried. Das kulturelle Imaginäre: Eine Funktionsgeschichte des amerikanischen Romans, 1790-1900. Frankfurt/Main: Suhrkamp, 1997.

Gell-Mann, Murray. The Quark and the Jaguar: Adventures in the Simple and the Complex. London: Abacus, 1995a. 
Gell-Mann, Murray. "What is Complexity?” Complexity 1.1 (1995b): 16-19.

Glomb, Stefan, Stefan Horlacher, eds. Beyond Extremes: Repräsentation und Reflexion von Modernisierungsprozessen im zeitgenössischen britischen Roman. Tübingen: Narr, 2004.

Gurr, Jens Martin. "Das Ruhrgebiet als Herausforderung für Kategorien und Ansätze der Stadtforschung." Dérive: Zeitschrift für Stadtforschung 58 (2015): 23-26.

Gurr, Jens Martin. "Urbanity, Urban Culture and the European Metropolis." Britannien und Europa: Studien zur Literatur-, Geistes- und Kulturgeschichte; Festschrift für Jürgen Klein. Ed. Michael Szczekalla. Frankfurt/Main: Peter Lang, 2010. 241-255.

Gurr, Jens Martin. "Views on Violence in Shelley's Post-Peterloo Prose and Poetry: Contradiction, Ambivalence, Ambiguity?" Romantic Ambiguities: Abodes of the Modern. Ed. Sebastian Domsch, Christoph Reinfandt, Katharina Rennhak. [Studies in English Romanticism 20]. Trier: WVT, 2017. 83-93.

Gurr, Jens Martin. “'Without contraries is no progression': Emplotted Figures of Thought in Negotiating Oppositions, Funktionsgeschichte and Literature as 'Cultural Diagnosis'." Text or Context: Reflections on Literary and Cultural Criticism. Ed. Rüdiger Kunow, Stephan Mussil. Würzburg: Königshausen \& Neumann, 2013. 59-77.

Gurr, Jens Martin, Martin Butler. “Against the 'Erasure of Memory' in Los Angeles City Planning: Strategies of Re-Ethnicizing L.A. in Digital Fiction.” Selling EthniCity. Ed. Olaf Kaltmeier. London: Ashgate, 2011. 145-163.

Gurr, Jens Martin, Martin Butler. "On the 'Cultural Dimension of Sustainability' in Urban Systems: Urban Cultures as Ecological 'Force-Fields' in Processes of Sustainable Development." Healthy and Liveable Cities/Gesunde und lebenswerte Städte. Ed. Stefanie Caeners, Michael Eisinger, Jens Martin Gurr, J. Alexander Schmidt. Stuttgart: avedition, 2013. 138-151.

Gurr, Jens Martin, Ute Schneider. "Strategien zur Bewältigung urbaner Komplexität: Zum Zusammenwirken visueller, verbaler und quantitativer Modelle.” Komplexität und Einfachheit: DFG-Symposion 2015. Ed. Albrecht Koschorke. Stuttgart: Metzler, 2017. 256-275.

Gurr, Jens Martin, Christian Walloth. "Introduction: Towards a Transdisciplinary Understanding of Complex Urban Systems." Understanding Complex Urban Systems: Multidisciplinary Approaches to Modeling. Ed. Christian Walloth, Jens Martin Gurr, J. Alexander Schmidt. Heidelberg, New York: Springer, 2014. $1-12$.

Gymnich, Marion, Ansgar Nünning, eds. Funktionen von Literatur: Theoretische Grundlagen und Modellinterpretationen. Trier: WVT, 2005.

Haken, Herman, Juval Portugali. "The Face of the City is its Information." Journal of Environmental Psychology 23.4 (2003): 385-408.

Hall, Peter. The World Cities. London: Weidenfeld \& Nicolson, 1966.

Harding, Desmond. "Ulysses and Manhattan Transfer: A Poetics of Transatlantic Literary Modernism.” Harding. Writing the City: Urban Visions \& Literary Modernism. New York: Routledge, 2003.97-136.

Harvey, David. The Condition of Postmodernity: An Inquiry into the Origins of Cultural Change. Oxford, London: Blackwell, 1989.

Hassenpflug, Dieter. "Once Again: Can Urban Space be Read?" Reading the City: Developing Urban Hermeneutics/Stadt lesen: Beiträge zu einer urbanen Hermeneutik. Ed. Dieter Hassenpflug, Nico Giersig, Bernhard Stratmann. Weimar: Verlag der Bauhaus-Universität, 2011. 49-58. 
Hassenpflug, Dieter. "Walter Benjamin und die Traumseite der Stadt." Hassenpflug. Reflexive Urbanistik: Reden und Aufsätze zur europäischen Stadt. Weimar: Verlag der Bauhaus-Universität, 2006. 7-22.

Hörisch, Jochen. Das Wissen der Literatur. Munich: Fink, 2007.

Huyssen, Andreas. Present Pasts: Urban Palimpsests and the Politics of Memory. Palo Alto: Stanford University Press, 2003.

Iser, Wolfgang. Das Fiktive und das Imaginäre: Perspektiven literarischer Anthropologie. Frankfurt/Main: Suhrkamp, 1993.

Jacobs, Jane. The Death and Life of Great American Cities. New York: Random House, 1961.

Keunen, Bart. "Living with Fragments: World Making in Modernist City Literature." Modernism. Ed. Astradur Eysteinsson, Vivian Liska. Amsterdam: Benjamins, 2007. 271-290.

Keunen, Bart, Bart Eeckhout. "Whatever Happened to the Urban Novel?” Postmodern New York City: Transfiguring Spaces - Raum-Transformationen. Ed. Günter Lenz, Utz Riese. Heidelberg: Winter, 2003. 53-69.

Koschorke, Albrecht. Wabrheit und Erfindung: Grundzüge einer Allgemeinen Erzähltheorie. Frankfurt/Main: Fischer, ${ }^{3} 2013$.

Lefebvre, Henri. The Production of Space [1974]. Trans. Donald Nicholson-Smith. Oxford: Blackwell, 1991.

Lehan, Richard. The City in Literature: An Intellectual and Cultural History. Berkeley: University of California Press, 1998.

Lenz, Günter, Utz Riese, eds. Postmodern New York City: Transfiguring Spaces - RaumTransformationen. Heidelberg: Winter, 2003.

Li, Ming, Paul Vitányi. An Introduction to Kolmogorov Complexity and its Applications. New York, Berlin: Springer, 1993.

Lindner, Rolf. "Textur, 'imaginaire', Habitus. Schlüsselbegriffe der kulturanalytischen Stadtforschung." Die Eigenlogik der Städte: Neue Wege für die Stadtforschung. Ed. Helmuth Berking, Martina Löw. Frankfurt/Main: Campus, 2008. 83-94.

Mahr, Bernd. "Modelle und ihre Befragbarkeit: Grundlagen einer allgemeinen Modelltheorie." Erwägen - Wissen - Ethik/Deliberation - Knowledge - Ethics: Forum für Erwägungskultur/Forum for Deliberative Culture 26.3 (2015): 329-342.

Mainzer, Klaus. Thinking in Complexity: The Computational Dynamics of Matter, Mind and Mankind. Berlin: Springer, ${ }^{5} 2007$.

Martindale, Charles. "Ruins of Rome: T.S. Eliot and the Presence of the Past." Arion 3.2-3 (1995): 102-140.

Mattheis, Lena. Translocal Narratability in Contemporary Anglophone Fiction. Dissertation manuscript, University of Duisburg-Essen, 2019.

McNamara, Kevin R., ed. The Cambridge Companion to the Literature of Los Angeles. Cambridge: Cambridge University Press, 2010.

Moretti, Franco. Atlas of the European Novel, 1800-1900. London, New York: Verso. 1998.

Portugali, Juval. Complexity, Cognition and the City. Understanding Complex Systems (UCS). Berlin, Heidelberg: Springer, 2011.

Portugali, Juval. "Complexity Theories of Cities: Achievements, Criticism and Potentials." Complexity Theories of Cities Have Come of Age: An Overview with Implications to Urban Planning and Design. Ed. Juval Portugali, Han Meyer, Egbert Stolk, Ekim Tan. Berlin, Heidelberg: Springer, 2012a. 47-62.

Portugali, Juval. "Complexity Theory as a Link Between Space and Place.” Environment and Planning A 38 (2006): 647-664. 
Portugali, Juval. "Introduction." Complexity Theories of Cities Have Come of Age: An Overview with Implications to Urban Planning and Design. Ed. Juval Portugali, Han Meyer, Egbert Stolk, Ekim Tan. Berlin, Heidelberg: Springer, 2012b. 1-5.

Portugali, Juval. Self-Organization and the City. Berlin, Heidelberg: Springer, 2000.

Portugali, Juval, Han Meyer, Egbert Stolk, Ekim Tan, eds. Complexity Theories of Cities Have Come of Age: An Overview with Implications to Urban Planning and Design. Berlin, Heidelberg: Springer, 2012.

Read, Stephen. "Meaning and Material: Phenomenology, Complexity, Science and 'Adjacent Possibilities'." Complexity Theories of Cities Have Come of Age: An Overview with Implications to Urban Planning and Design. Ed. Juval Portugali, Han Meyer, Egbert Stolk, Ekim Tan. Berlin, Heidelberg: Springer, 2012. 105-127.

Richter, Klaus, Jan-Michael Rost. Komplexe Systeme. Frankfurt/Main: Fischer, 2002.

Rossetto, Tania. “Theorizing Maps with Literature.” Progress in Human Geography 38.4 (2014): 513-530.

Sassen, Saskia. The Global City: New York, London, Tokyo. Princeton: Princeton University Press, ${ }^{2} 2001$.

Scherpe, Klaus R., ed. Die Unwirklichkeit der Städte: Großstadtdarstellungen zwischen Moderne und Postmoderne. Reinbek: Rowohlt, 1988.

Schneider, Ute. "Die Farbe der Religion: Topographie und Topik der 'Deux France'." Journal of Modern European History 9 (2011a): 117-139.

Schneider, Ute. "Inquiries or Statistics? Agricultural Surveys and Methodological Considerations in the Nineteenth Century." The Golden Age of State Enquiries. Ed. Nadine Vivier. Turnhout: Brepols, 2014. 43-57.

Schneider, Ute. Die Macht der Karten: Eine Geschichte der Kartographie vom Mittelalter bis heute. 3rd enl. and updated ed. Darmstadt: Primus, 2011b.

Schneider, Ute. “'Den Staat auf einem Kartenblatt übersehen!' Die Visualisierung der Staatskräfte und des Nationalcharakters." Kartenwelten: Der Raum und seine Repräsentation in der Neuzeit. Ed. Christof Dipper, Ute Schneider. Darmstadt: Primus, 2006. 11-25.

Schultz, Rüdiger. "Uncertainty in Urban Systems: How to Optimize Decision Making Using Stochastic Programming." Understanding Complex Urban Systems: Multidisciplinary Approaches to Modeling. Ed. Christian Walloth, Jens Martin Gurr, J. Alexander Schmidt. Berlin, Heidelberg: Springer, 2014.

Sharpe, William, Leonard Wallock. "From 'Great Town' to 'Nonplace Urban Realm': Reading the Modern City." Visions of the Modern City: Essays in History, Art, and Literature. Ed. Sharpe, Wallock. Baltimore: Johns Hopkins University Press, 1987. 1-50.

Simmel, Georg. "The Metropolis and Mental Life” [1903]. The City Cultures Reader. Ed. Malcolm Miles, Tim Hall, Iain Borden. London: Routledge, ${ }^{22004 . ~ 12-19 . ~}$

Smuda, Manfred, ed. Die Großstadt als “Text.” Munich: Fink, 1992.

Stachowiak, Herbert. Allgemeine Modelltheorie. Vienna, New York: Springer, 1973.

Suttles, Gerald D. "The Cumulative Texture of Local Urban Culture." American Journal of Sociology 90.2 (1984): 283-304.

Teske, Doris. Die Vertextung der Megalopolis: London im Spiel postmoderner Texte. Trier: WVT, 1999.

Walloth, Christian. "Emergence in Complex Urban Systems: Blessing or Curse of Planning Efforts?" Understanding Complex Urban Systems: Multidisciplinary Approaches to Modeling. Berlin, Heidelberg: Springer, 2014. 121-132. 


\section{Urban Complexity Research}

Walloth, Christian. Emergent Nested Systems: A Theory of Understanding and Influencing Complex Systems as well as Case Studies in Urban Systems. Berlin, Heidelberg: Springer, 2016.

Walloth, Christian, Jens Martin Gurr, J. Alexander Schmidt, eds. Understanding Complex Urban Systems: Multidisciplinary Approaches to Modeling. Berlin, Heidelberg: Springer, 2014.

Wellershoff, Dieter. Literatur und Lustprinzip. Cologne: Kiepenheuer \& Witsch, 1973.

Wirth-Nesher, Hana. City Codes: Reading the Modern Urban Novel. Cambridge: Cambridge University Press, 1996.

Wolfreys, Julian. Writing London: The Trace of the Urban Text from Blake to Dickens. London: Palgrave, 1998.

Wolfreys, Julian. Writing London 2: Materiality, Memory, Spectrality. London: Palgrave, 2004.

Wolfreys, Julian. Writing London 3: Inventions of the City. London: Palgrave, 2007. 